\title{
STATIC ANALYSIS OF ALLOY WHEEL USING ANSYS15.0
}

\author{
Jaspreet Singh ${ }^{1}$, Siddhartha Saha ${ }^{2}$ \\ ${ }^{I}$ Student, Mechanical Engineering, BBSBEC, Punjab, India \\ ${ }^{2}$ Assistant Professor, Mechanical Engineering, BBSBEC, Punjab, India
}

\begin{abstract}
Wheels are the main components of the car. The wheels with tires provide the better cushioning effect to the car. Without engine a car may be towed but at the same time a car cannot be towed without wheels. . The main requirement of the vehicle or automobile tires are it must be perfect to perform its all the functions. Reverse engineering is a good method to redesign the old component. The wheels have to pass different tests for best performance like static analysis, vibration analysis etc. In this project a wheel was considered for the analysis. During the part of the thesis project aluminium alloy was carried out for the FEA analysis. Design is an important manufacturing activity which provides the quality of the product. The 3-dimensional model of the alloy wheel was designed by using the technology reverse engineering. The 3-dimensional model was designed in the modelling software CATIA v5. and further it was imported to the ANSYS 15.0 by using IGES format. The finite element analysis of the model was meshed by using 10 node tetrahedron solid element. The static condition was chosen for the analysis. This was constrained in all degree of freedom at the bolt. The pressure was applied on the outer rim surface of the alloy wheel. In the analysis, the results of the equivalent stress, safety factor, and deformation were calculated. In this analysis the von-misses stress were below the yield strength. All the results which were analyzed are good for the design which was drawn by reverse engineering.
\end{abstract}

Keywords: Alloy Wheel, Reverse Engineering, CATIA, Stress Analysis, ANSYS15.0 etc... - $* * *$

\section{INTRODUCTION}

The significance of wheel and tires in the vehicle can't be challenged. Without engine, Car may pull, but without the wheels, it is not possible. The wheel thru tires takes complete load, and decreases friction, and delivers cushioning effect to passenger by absorbing vibration due to road surface unevenness and support in steering control. The alloy of conventional disc wheel in incident of car and wire rims as in case of motorbike has better visual looks and easy of manufacturing.

The main requirements of an automobile wheel are:-

1. It should be as bright as possible so that unsprang mass is least.

2. It should be robust enough to perform the directly above functions.

3. It should be stable statically along with dynamically.

4. It should be possible to eliminate or mount the rim easily.

5. Its material should not fail with weathering and period of time .In case, the material is come in contact to corrosion, it must be given suitable defensive treatment.

\subsection{Type of wheels (according to material)}

Steel and light alloy are the leading materials used in a wheel, and several of the composite materials are involved such as glass-fiber are utilized for different wheels. These wheels are established on the use of less weight metals such as aluminum and magnesium and have become very famous in the market. These wheels become popular for the original equipment vehicle in Europe in 1960(year) and for the extra tire in United States in 1970(year) have quickly .

\subsection{Aluminum Alloy}

Aluminum is a metal with features of outstanding lightness, thermal conductivity, corrosion conflict, features of casting, little temperature, machine processing and reusing, etc. They are classically lighter for the same strength and provide well heat conduction and better cosmetic appearance above steel wheels. The modern light alloy wheels were manufactured of magnesium alloys. This metals leading advantage is reduced weight, high precision and design selections of the wheel. This metal is suitable for energy conservation because it is possible to reuse aluminum easily.

\section{RIM NOMENCLATURE SPECIFICATIONS}

1. Wheel: Wheel is usually composed of rim and disc.

2. Rim: This is a portion where the tire is fitted.

3. Disc: This is a region of the rim wherever it is fixed to the axle Centre.

4. Offset: Its a distance among wheel mounting surface where it is attached to hub and the centerline of rim.

5. Flange: The flange is a portion of rim, which grasps the both beads of the tire.

6. Bead Seat: Bead seat comes in contact thru the bead face and is a portion of rim, which grasps the tire in a radial way. 7. Hump: Hump is bump what was put on the bead seat for the bead to inhibit the tire from slipping off the rim while the vehicle is moving mode.

8. Well: This is a portion of rim with depth and width to ease tire mounting and deduction from the rim. 


\subsection{Benefits of Fitting Alloy Wheel in Vehicle}

The alloy wheels are beneficial for automobiles. These will give a better look to the vehicle and it will make our vehicle outstanding in today's crowd. These will reduce the unsprang weight of a automobile fitted with usual steel wheels. The main benefit is the reduced unsprang weight for more precise steering as well as less utilization of the fuel. Alloy wheels are excellent conductor of the heat, improving heat dissipations from braking. It also reduces the brake failure under various demanding conditions. Alloy wheels also give better mounting of the tyre on the rim of the wheel and also helps in better turning.

\subsection{Alloy Wheel Specifications}

The alloy wheel was designed by using the wheel specifications which are described below with figure(2.2) and table(2.2) specifications:-

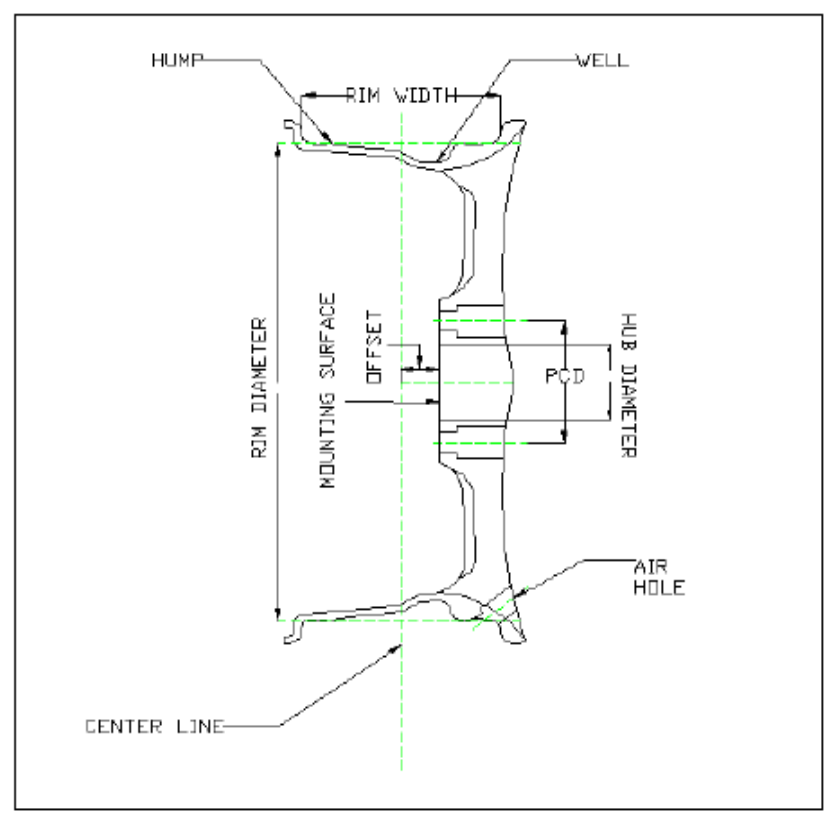

Fig-2.2 Specification of wheel

Table -2.2 Specifications of wheel

\begin{tabular}{|l|l|}
\hline Specifications & Measurements $(\mathrm{mm})$ \\
\hline Rim diameter & 355.6 \\
\hline Rim width & 152 \\
\hline Offset & 40 \\
\hline PCD & 100 \\
\hline Hub diameter & 72 \\
\hline
\end{tabular}

\section{MODELLNG IN CATIA AND ANALYSIS}

\subsection{Modelling}

Modelling of the wheel was done by CATIA and Reverse engineering (manual). These are two methods which are used to convert a physical model as shown in figure (3.1.1) into digital model as shown in figure (3.1.3). The steps are following:-

\subsubsection{Physical Model}

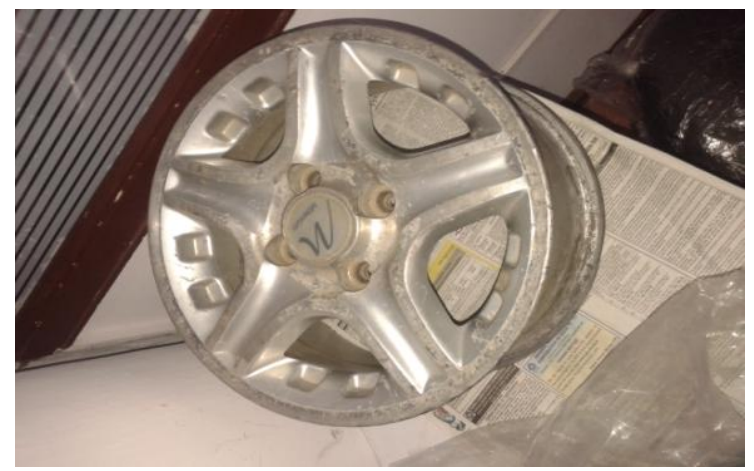

Fig-3.1.1 Physical model of wheel

\section{Step 3.1.2}

Shaft command was used for new sketch with the required dimensions using the Centre line at the angle of 360

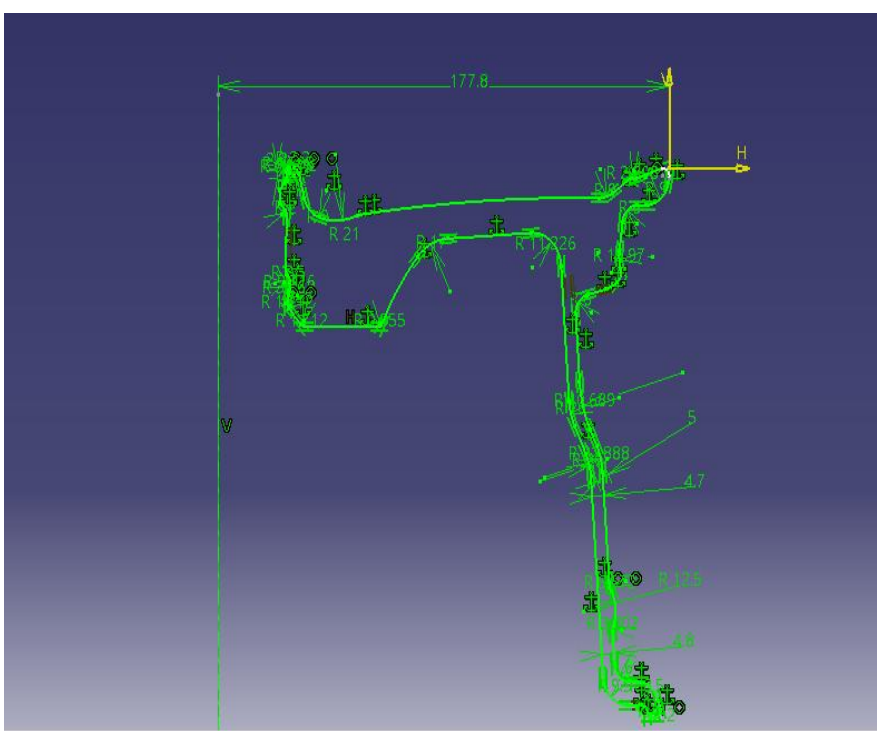

Fig-3.1.2 Sketch of section

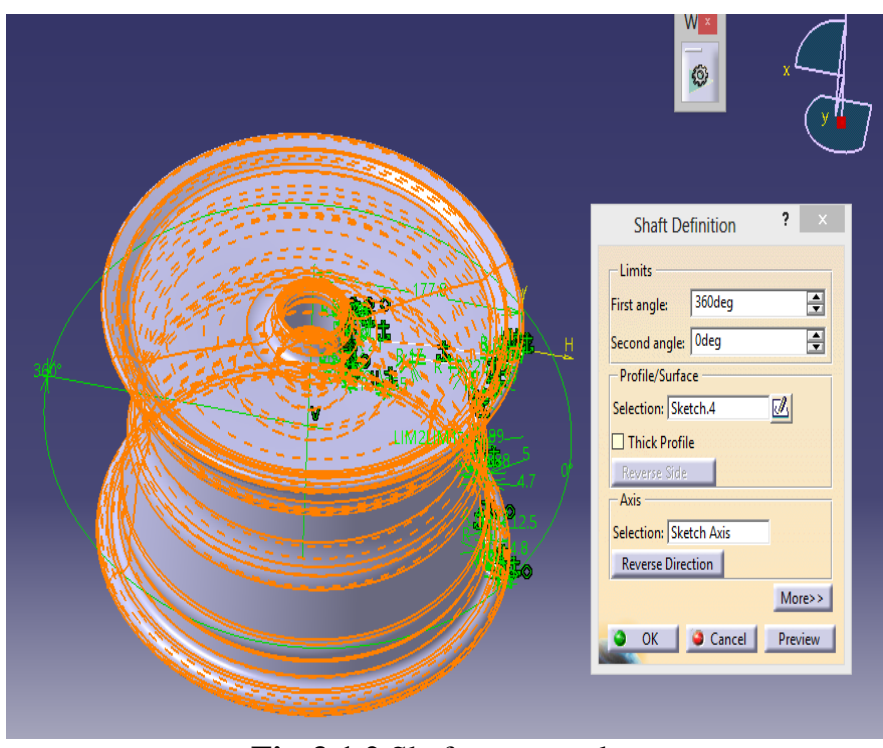

Fig-3.1.2 Shaft command 


\section{Step 3.1.3}

After the step 3.1.2 a sketch was drawn on the upper surface of the wheel .The pad command and the split command was used for spokes gap.

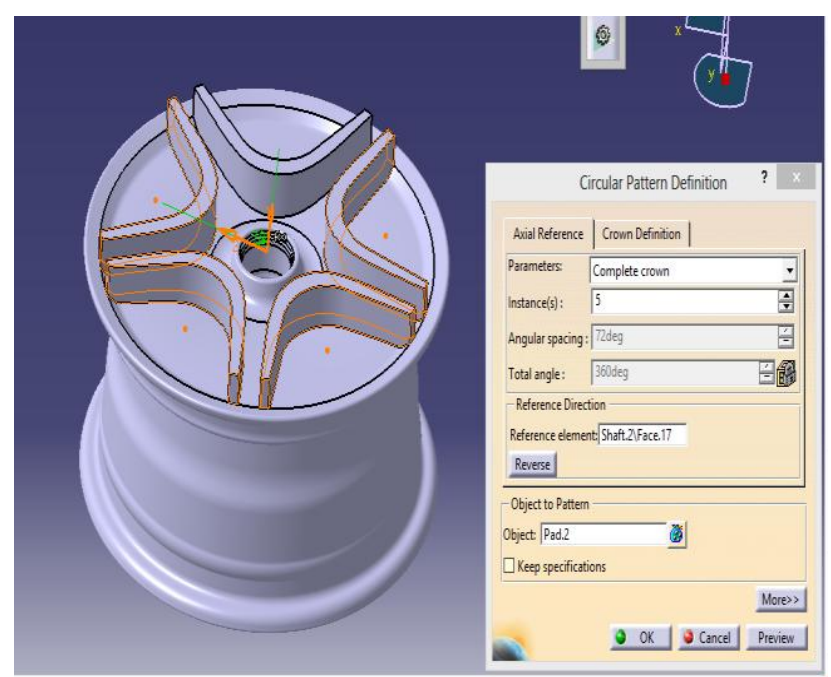

Fig-3.1.3 Spokes formation

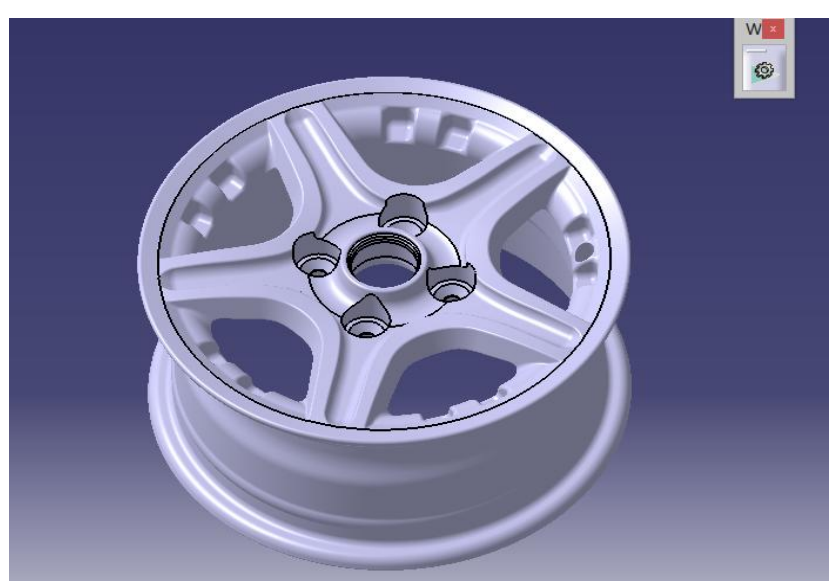

Fig-3.1.3 split command and final view

\subsection{Meshing}

The model was meshed with 10 node tetrahedron mesh and the elements were 208273and nodes were 347677

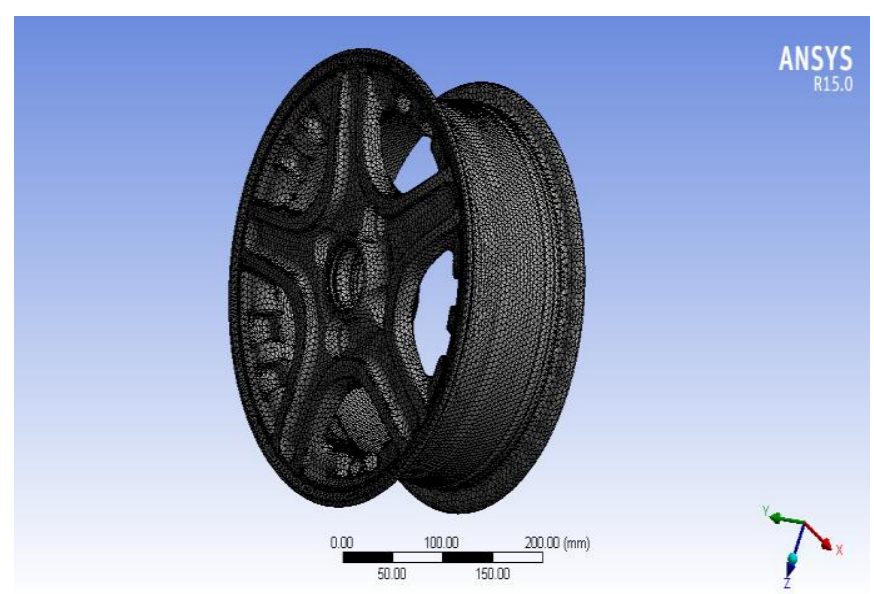

Fig-3.2 Meshing of wheel

\subsection{Boundary Conditions}

In this project the alloy wheel was constrained in all degree of freedom using cylindrical support at the bolts.

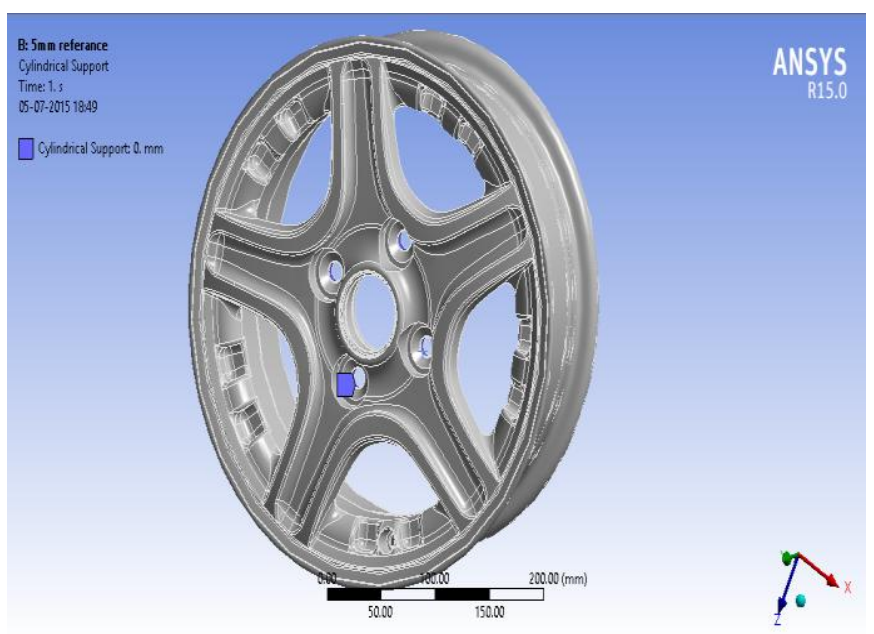

Fig-3.3 Boundry conditions

\subsection{Loading Conditions}

According to the boundary conditions a load of 200KPa [1] was applied on the circumferential area of the rim.

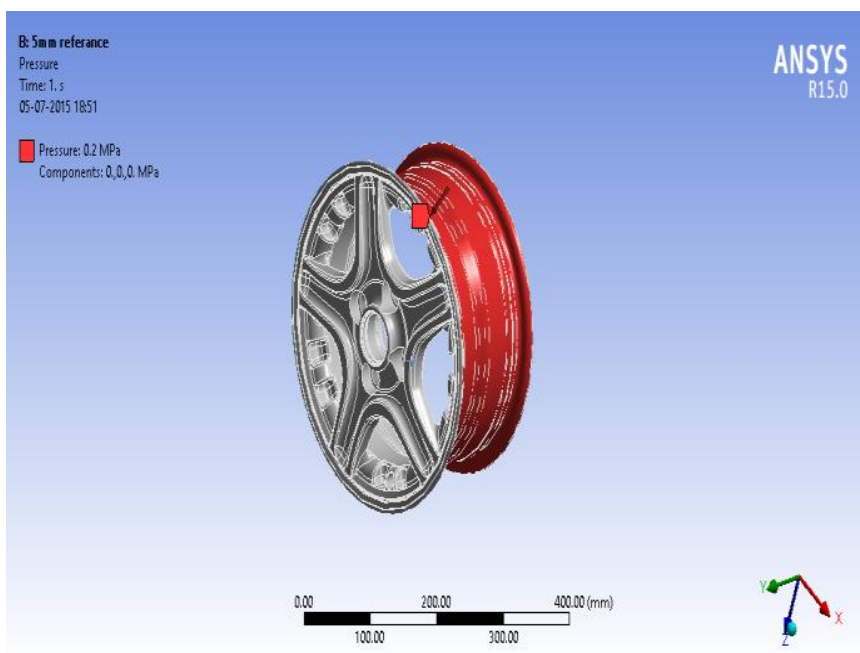

Fig-3.4 Loading conditions

\section{RESULTS}

The CATIA file was imported into the ANSYS15.0 as iges for the analysis.Boundry and loading condtions were applied as dicussed above 3.2 and 3.3. and the results are in table(4) 


\subsection{Equivalent Stress}

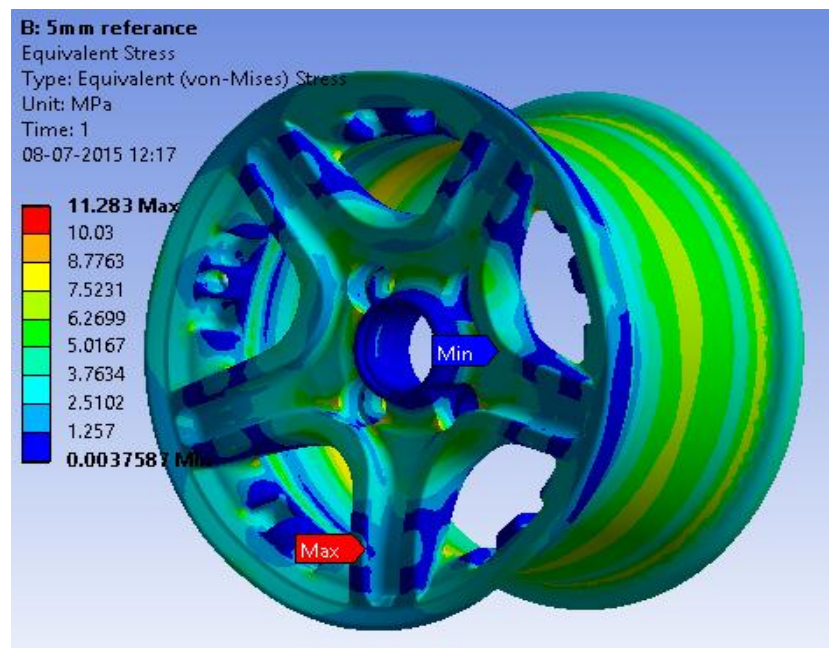

Fig-4.1 Equivalent stress

\subsection{Deformation}

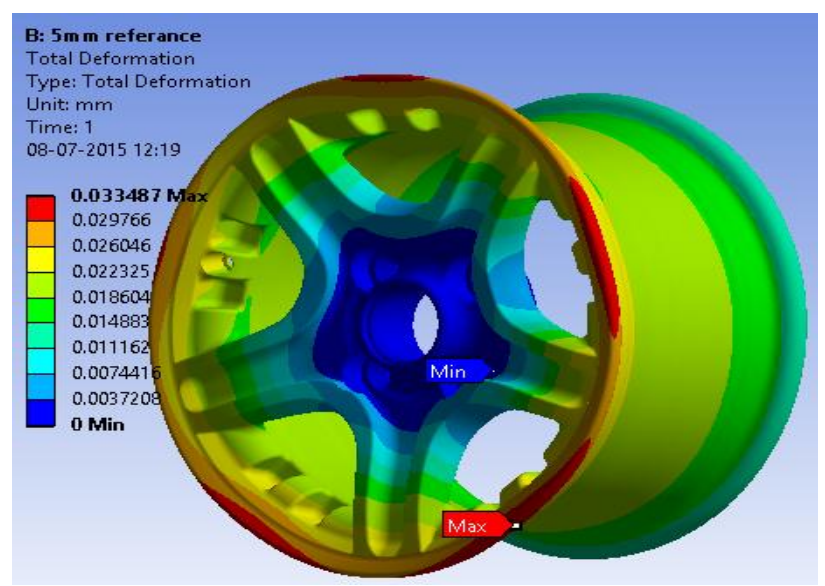

Fig-4.2 Deformation

\subsection{Safety Factor}

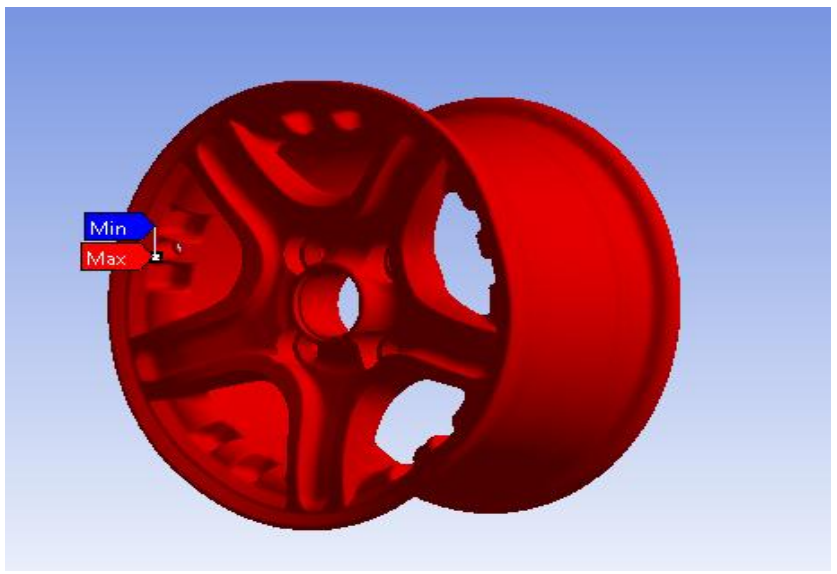

Fig-4.3 Safety factor

Table -4 Results in analysis

\begin{tabular}{|l|l|}
\hline Name & Values \\
\hline Equivalent stress & $11.283 \mathrm{MPa}$ \\
\hline Deformation & $0.033 \mathrm{~mm}$ \\
\hline Safety factor & 21 \\
\hline
\end{tabular}

\section{CONCLUSION}

1. After completion of the meshing, the load of $200 \mathrm{KN}$ was applied on the circumference of the rim. The equivalent stress of wheel maximum was $11.283 \mathrm{MPa}$. The maximum equivalent stress was at the spokes corner and is minimum at the inner side of the spokes as shown in figure(4.1) and it was well below the yield point of the Al alloy hence safe design at $200 \mathrm{KN}$.

2. The total deformation of alloy wheel was maximum $0.033 \mathrm{~mm}$. Maximum deformation was at the circumference of the wheel and minimum at the bolt portion as shown in figure (4.2).

3. The safety factor was minimum and maximum at the air pressure hole i.e. 21 as shown in figure (4.3).

\section{REFERENCES}

[1]. P. Meghashyam, S. Girivardhan Naidu and N. Sayed Baba(2013), "Design and Analysis of Wheel Rim using CATIA \& ANSYS", International Journal of Application or Innovation in Engineering \& Management (IJAIEM), Volume 2, Issue 8, ISSN 2319 - 4847.

[2]. N. Satyanarayana \& Ch.Sambaiah (2012), "Fatigue Analysis of Aluminum Alloy Wheel under Radial Load", International Journal of Mechanical and Industrial Engineering (IJMIE), ISSN No. 2231 -6477, Vol-2, Issue-1. [3]. P. Ramamurthy Raju , B. Satyanarayana, K. Ramji , K. Suresh Babu(2007), "Evaluation of fatigue life of aluminum alloy wheels under radial loads", Science Direct, Engineering Failure Analysis 14 (2007) 791-800.

[4]. M.V. Prabha and Pendyala Veera Raju(2012), "Design and development of aluminum alloys", International Journal of Advanced Science, Engineering and Technology,ISSN 2319-5924,Vol 1, Issue 2, 2012, pp 5560.

[5]. S Vikranth Deepak, C Naresh and Syed, Altaf Hussain (2012), "Modelling and analysis of alloy wheel for four wheeler vehicle”, ISSN 2278 - 0149, Vol. 1, No. 3. 